\title{
Pulmonary vascular lesions in the toxic oil syndrome in Spain
}

\author{
P FERNÁNDEZ-SEGOVIANO, A ESTEBAN, R MARTINNEZ-CABRUJA
}

From the Department of Pathology and Intensive Care Unit, Hospital Central de la Cruz Roja, Madrid, Spain

ABSTRACT A histological study was made of pulmonary arteries at the necropsies of nine patients who died after the ingestion of denatured rapeseed oil during the epidemic which occurred in Spain in May 1981. Lesions found in the elastic pulmonary arteries were characterised by pronounced intimal proliferation of an oedematous nature, accumulation of large vacuolated cells within the media, and loss of vascular smooth muscle. In muscular pulmonary arteries there was pronounced medial hypertrophy and intimal proliferation, which was so severe in one case that it completely occluded the arterial lumen. Foamy cells were found in the intima. Muscularisation was seen in the walls of pulmonary arterioles.

Cases of pulmonary hypertension have been described secondary to the ingestion of herbal infusions $^{1-4}$ and the intravenous administration of lipids. ${ }^{5}$ Similar cases have been reported after the use of various pharmacological agents. ${ }^{6}$ From 1965 to 1968 an increase in the incidence of primary pulmonary hypertension was seen in West Germany, Austria, and Switzerland, coinciding with the prescription of aminorex ${ }^{7}$ (2-amino-5-phenyl-2oxozoline) to obese people for weight reduction. These lesions have never been successfully reproduced in the laboratory. An experimental model for the study of pulmonary hypertension has, however, been achieved by administering preparations derived from certain species of Crotalaria (C spectabilis, $C$ fulva, $C$ laburnoides) to rats and mice. ${ }^{1-4} \mathrm{~A}$ case has also been reported from Tanzania ${ }^{3}$ that can reasonably be suspected as being of this aetiology. Similar lesions were found at necropsy in three infants with pulmonary lesions who had had parenteral nutrition with lipids. ${ }^{5}$ In Spain we have witnessed an epidemic produced by ingestion of denatured rapeseed oil which affected about 18000 people, of whom 327 have died so far. Some of these patients developed vascular lesions characteristic of pulmonary arterial hypertension, accompanied by general vascular damage.$^{89}$ In this paper we describe the vascular pulmonary lesions found at necropsy in

Address for reprint requests: Dra Fernández-Segoviano, Departamento de Anatomía Patológica, Hospital Central de la Roja, Avda, Reina Victoria 26, Madrid (3), Spain.

Accepted 6 May 1983 nine patients who suffered from this disease.

\section{Methods}

We studied the postmortem appearances in nine patients who died after ingestion of rapeseed oil. $\stackrel{\mathbb{Q}}{\varrho}$ They were admitted to hospital during the epidemic, $\overrightarrow{\vec{O}}$ which began in Spain in May 1981 and was characterised by dry cough, dyspnoea, fever, and cutaneous phenomena. These symptoms resolved spon-? taneously 15-20 days after their onset. None of our patients died during this initial period; the first death occurred 45 days and the last 243 days after the $x$ beginning of the symptoms.

In each case the necropsy was carried out immediately after death. The lungs were placed in $4 \%$ formaldehyde. Blocks taken from each lobe were embedded in paraffin. Sections $5 \mu \mathrm{m}$ thick음 were cut and stained with haematoxylin and eosin $>$ and with orcein (for elastic tissue), with a van Gieson counterstain for connective tissues such as N collagen and smooth muscle. The sections were examined under a microscope with an eyepiece micro- 0 meter to measure the diameter of the arterial wall $\omega$ and the thickness of the media. The diameter was? calculated for arteries where the section was circu-co lar, the mean of two measurements at right angles to one another being taken. The same arteries were? used to measure the thickness of the media; in this case the average of four measurements taken at dif- + ferent levels was calculated. The thickness of the $\stackrel{\mathbb{Q}}{\oplus}$ media was expressed as a percentage of the external $\stackrel{\Phi}{\varrho}$ diameter. 
Table 1 Immediate cause of death in the nine cases of toxic oil syndrome

\begin{tabular}{|c|c|c|c|}
\hline & Age & Sex & Cause of death \\
\hline 1 & 30 & $\mathbf{M}$ & Mesenteric thrombosis. \\
\hline 2 & 41 & $\mathbf{M}$ & $\begin{array}{l}\text { Septic pulmonary thromboembolism, } \\
\text { secondary to thrombophlebitis. }\end{array}$ \\
\hline 3 & 31 & $\mathbf{F}$ & $\begin{array}{l}\text { Cardiac insufficiency. Desquamative } \\
\text { interstitial pneumonia. }\end{array}$ \\
\hline 4 & 33 & $\mathbf{M}$ & $\begin{array}{l}\text { Pulmonary thromboembolism. } \\
\text { Bacterial pneumonia. }\end{array}$ \\
\hline $\begin{array}{l}5 \\
6 \\
7 \\
8 \\
9\end{array}$ & $\begin{array}{l}77 \\
48 \\
53 \\
25 \\
27\end{array}$ & $\begin{array}{l}\mathbf{M} \\
\mathbf{F} \\
\mathbf{F} \\
\mathbf{F} \\
\mathbf{M}\end{array}$ & $\begin{array}{l}\text { Bacterial pneumonia. Sepsis. } \\
\text { Massive pulmonary thromboembolism. } \\
\text { Massive pulmonary thromboembolism. } \\
\text { Bacterial pneumonia (pseudomonas). } \\
\text { Bacterial pneumonia (pseudomonas). }\end{array}$ \\
\hline
\end{tabular}

\section{Results}

The studies relate to five men and four women. The age, sex, and immediate cause of death of each patient are shown in table 1 . The weight of each heart is shown in table 2, with the thickness of the wall of the right ventricle at the level at which the pulmonary artery leaves it.

The pulmonary vascular lesions found in the different types of vessels were as follows:

\section{ELASTIC PULMONARY ARTERIES}

In elastic pulmonary arteries (exceeding $1 \mathrm{~cm}$ in diameter-fig 1) the lesions most frequently met with were: (a) luminal dilatation in five of the nine cases; $(b)$ accumulation within the media of large vacuolated cells (foamy cells), which had a rather faint basophilic mucinous appearance in four cases; (c) pronounced intimal proliferation of an oedemat-
Table 2 Heart weight and right ventricular thickness

\begin{tabular}{lll}
\hline Case No & Weight of heart $(\mathrm{g})$ & Thickness of $R$ ventricle $(\mathrm{cm})$ \\
\hline 1 & 340 & $0 \cdot 4$ \\
2 & 350 & $0 \cdot 3$ \\
3 & 250 & $0 \cdot 4$ \\
4 & 210 & $0 \cdot 3$ \\
5 & 350 & $0 \cdot 3$ \\
6 & 210 & $0 \cdot 3$ \\
7 & 300 & $0 \cdot 3$ \\
8 & 320 & $0 \cdot 4$ \\
9 & 250 & $0 \cdot 2$ \\
\hline
\end{tabular}

ous nature in three cases; $(d)$ foamy cells in the intima in three cases; $(e)$ loss of vascular smooth muscle. In these arteries there were fasciculi of longitudinal muscle at the border of the media and adventitia.

\section{MUSCULAR PULMONARY ARTERIES}

The muscular pulmonary arteries $(100-1000 \mu \mathrm{m}$ diameter-figs 2-5) most affected were those from 100 to $300 \mu \mathrm{m}$ in diameter. The following features were found: (a) pronounced medial hypertrophy $(7 \cdot 2-9.7 \%)$ in five cases, $6.8 \%$ being taken as the upper limit of the thickness of the normal media in relation to the external diameter; $(b)$ loss of the vascular smooth muscle of part of the circumference of the media; $(c)$ intimal proliferation in seven cases, in one instance so severe that it completely occluded the arterial lumen. In three cases foamy cells were found in the intima and in three other cases there was perivascular infiltration by lymphocytes, plasma cells, histiocytes, eosinophils, and polymorphonuclear cells.

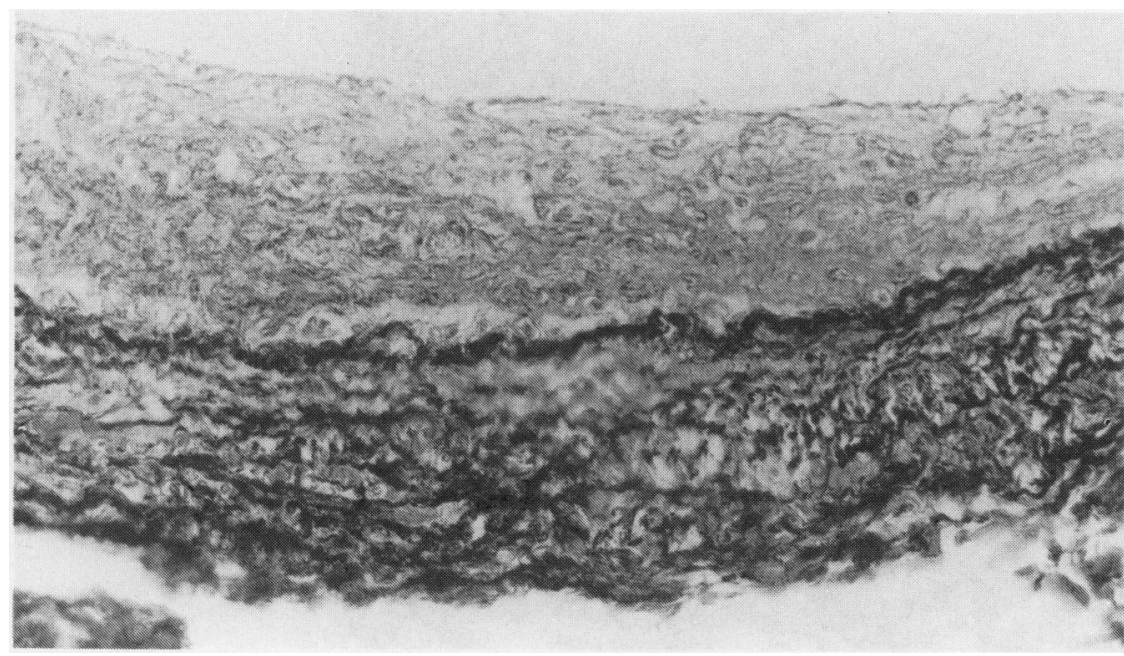

Fig 1 Transvere section of an elastic artery, showing great proliferation of the intima of an oedematous nature. (Orcein-van Gieson, $\times 400$.) 


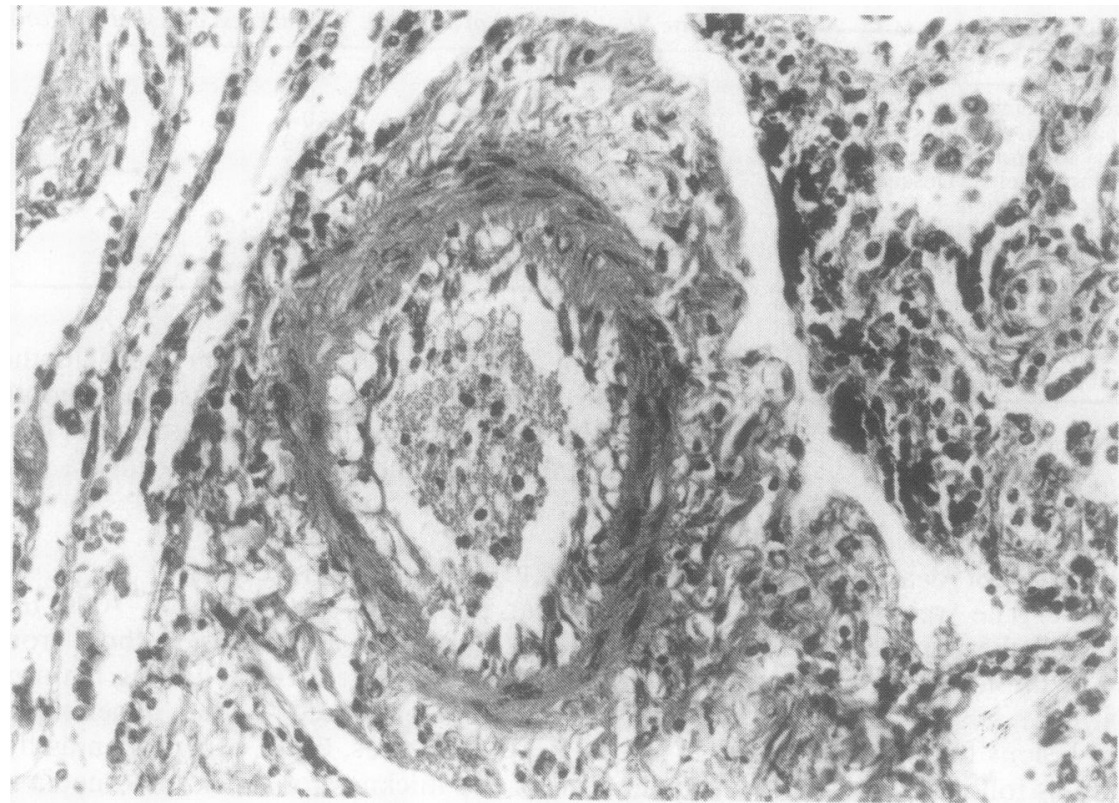

Fig 2 Transverse section of a muscular pulmonary artery, showing hyperplasia of the muscular layer and proliferation of the intima with infiltration by foamy cells. (Haematoxylin and eosin, $\times 400$.)

\section{PULMONARY ARTERIOLES}

Muscularisation of the wall of pulmonary arterioles (diameter less than $100 \mu \mathrm{m}$-fig 6) was seen in seven of the nine cases, intimal proliferation in five, and foamy cells in the intima in two. There were no pulmonary lesions in two of the nine patients. In none of the cases were there angiomatoid or plexiform lesions like those described in severe (grade IV) hypertensive pulmonary vascular disease.

In eight of the nine patients lesions were found in the systemic veins and arteries. These lesions were $\overline{\bar{B}}$ characterised by intimal proliferation with foamy

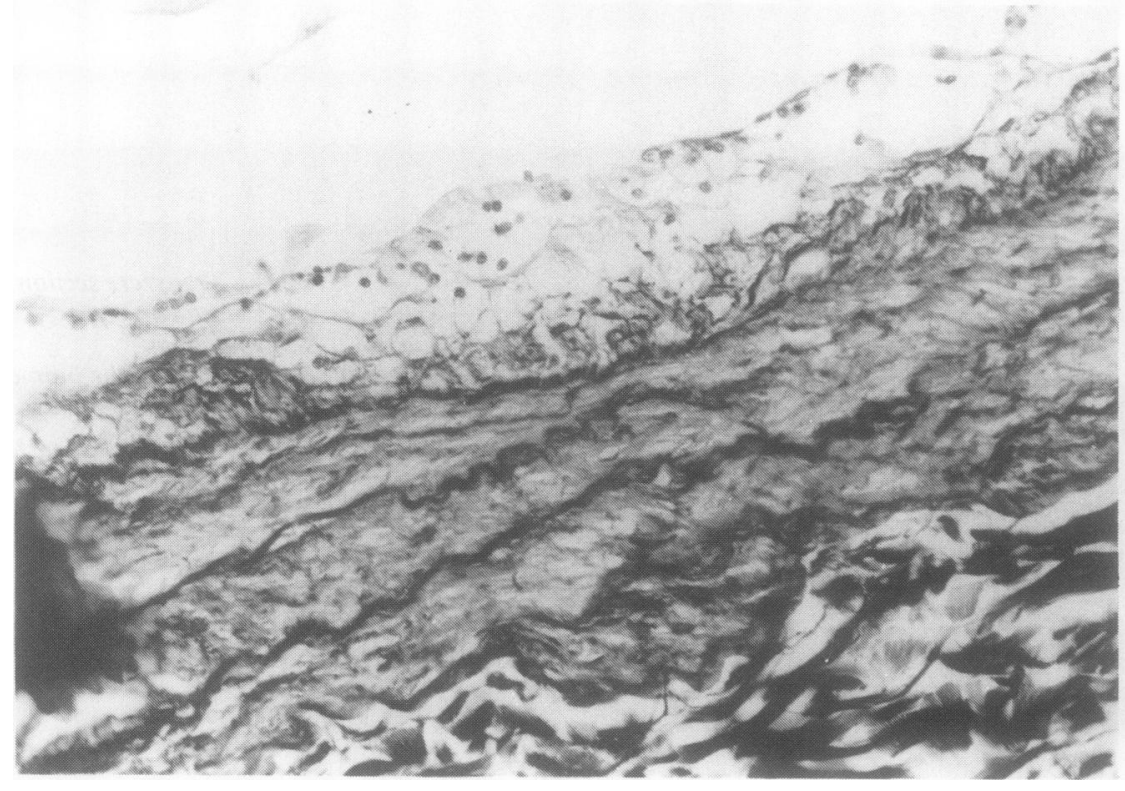
of a muscular pulmonary artery, showing proliferation of the intima and accumulations of foamy cells in the media and intima. (Orcein-van Gieson, ×400.) 


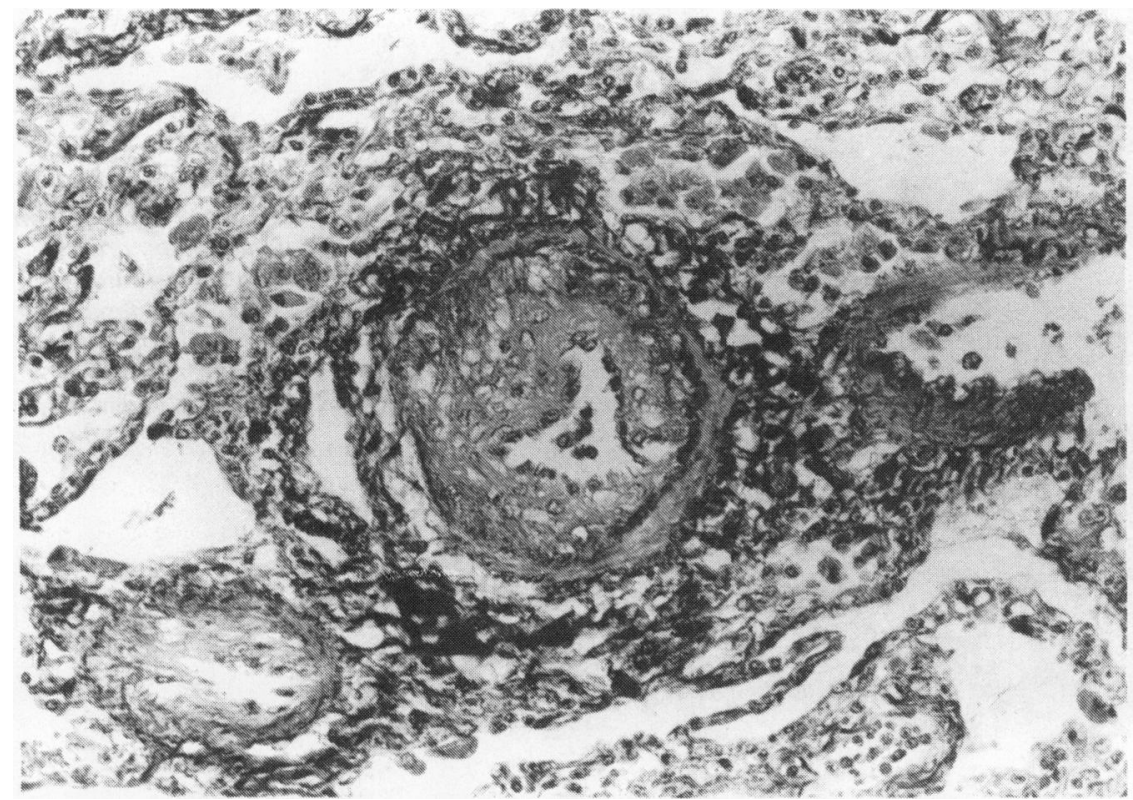

Fig 4 Transverse section of a muscular pulmonary artery, showing hypertrophy of the muscular layer and proliferaton of the intima. (Orcein-van Gieson, $\times 400$.)

cells present and by vasculitis with inflammatory infiltration of the vascular wall by lymphocytes, plasma cells, histiocytes, eosinophils, and polymorphonuclear leucocytes.

\section{Discussion}

The mechanism by which oral administration of some species of Crotalaria produces pulmonary

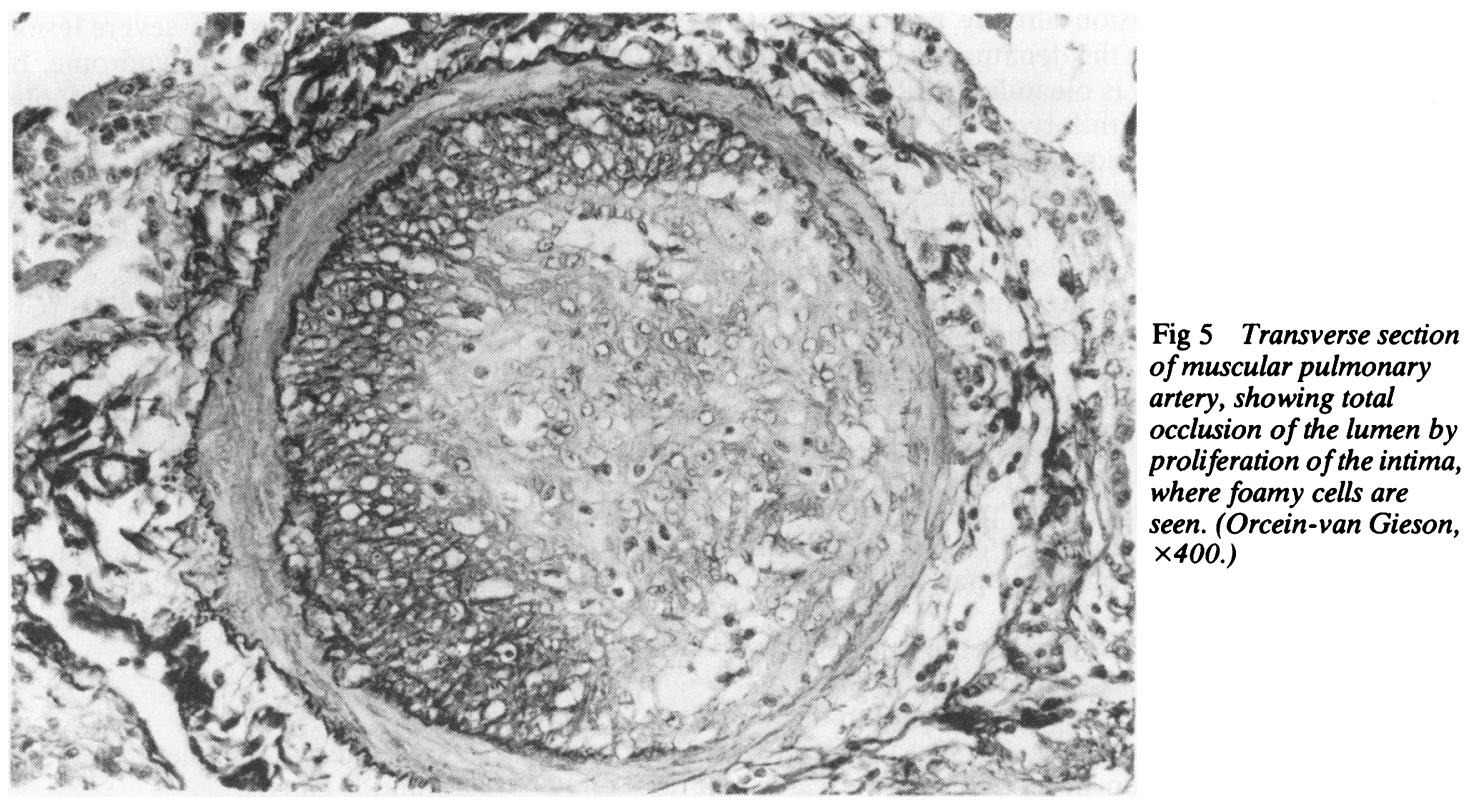

Fig 5 Transverse section occlusion of the lumen by proliferation of the intima, where foamy cells are seen. (Orcein-van Gieson, 


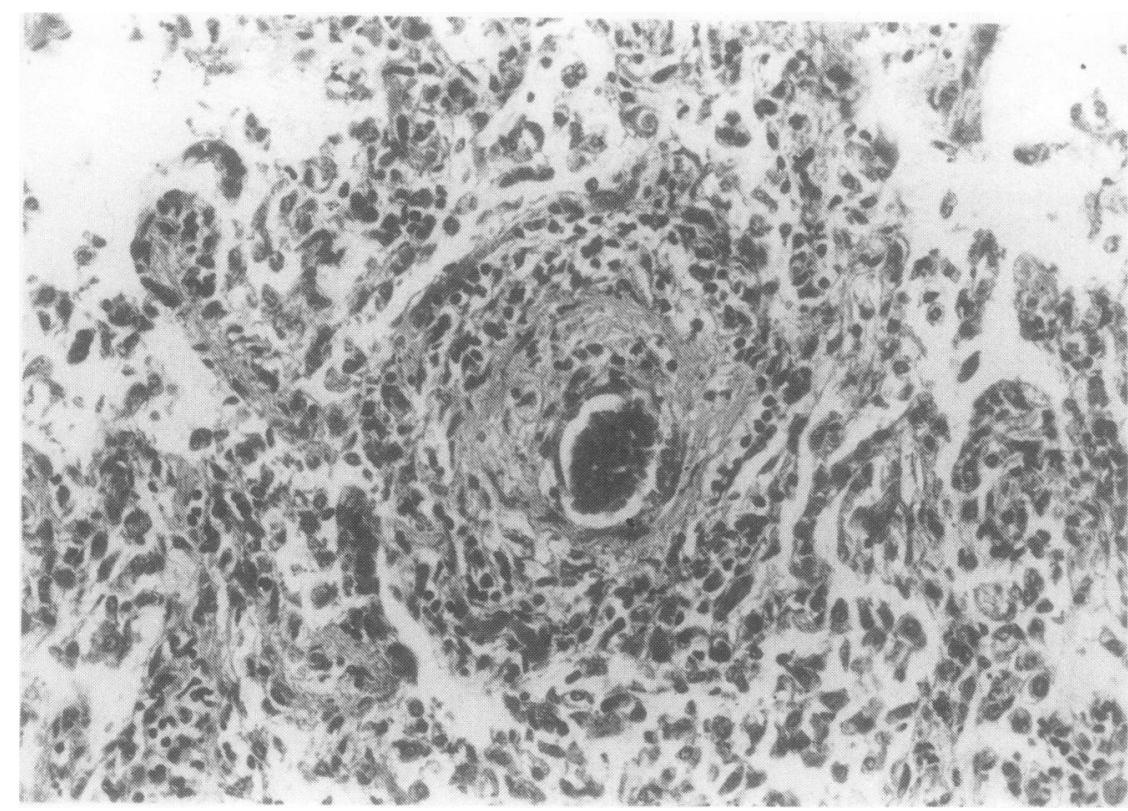

Fig 6 Transverse section of a pulmonary arteriole with muscularisation of the wall and inflamatory infiltration by foamy cells and lymphocytes.

(Haematoxylin and eosin, $\times 400$.)

hypertension is not clear. An active element found in the seeds, pyrollizidine alkaloid monocrotaline,${ }^{1-4}$ is metabolised by the liver into toxic substances, and these could be the factors triggering pulmonary hypertension. In the three cases cited above in which intravenous lipids had been administered no fundamental mechanism was established, and the lipids could have contributed to exacerbate a pulmonary vascular lesion already present. ${ }^{5}$ The basic toxic agent found in the denatured rapeseed oil ingested by our patients is oleanilid, produced as a reaction of acetanilide with fatty acids.

The similarity of the lesions observed in our cases to those associated with radiation, ${ }^{10}$ systemic sclerosis, ingestion of certain drugs, and intravenous nutrition rich in polyunsaturated lipids suggests that a similar mechanism may be responsible. An excess of polyunsaturated fatty acids in conjunction with the toxic compounds used to denature this type of oil could release free peroxide radicals. ${ }^{112}$ These radicals would act on the different cellular membranes, provoking structural and enzymatic modifications. Peroxide radicals can produce vascular lesions, similar to those found in our cases, which succeed in totally occluding the lumen and eventually cause intimal fibrosis.

Fibrogenesis ${ }^{11}$ would be stimulated by the proliferation and migration of myointimal cells because of elements passing from the blood through the damaged endothelium. Endothelial damage appears to have been the first lesion observed in those cases where lung biopsy was carried out during the acute phase of the illness.

Free radicals could also encourage vascular thrombosis ${ }^{13}$ by direct action on the platelets or by inhibiting the synthesis of prostacyclin at the level of the vascular endothelium and so facilitating adhesion of the platelets to the endothelium. This would explain the occurrence of thrombosis, which has been a frequent and in some cases very severe lesion in patients suffering from the toxic oil syndrome. In our series five of the nine patients had thrombotic lesions, which were the cause of death.

We are now carrying out experimental work on pigs. ${ }^{14}$ Denatured rapeseed oil, like that ingested by our patients, was given to one group. A second group received the same oil with vitamin $\mathrm{E}$, while a third group served as controls. Necropsies performed on these animals between $\mathbf{4 5}$ days and four months showed vascular lesions consistent with vasculitis, endothelial proliferation with vacuolisation of the cytoplasm, and focal necrosis as well as thrombosis. In the group that had received vitamin $E$ the lesions were less severe.

These results and the possibility of reproducing some of the lesions support the theory that free radicals are active in the production of this disease.

We gratefully acknowledge the comments made by Professors D Heath and P Harris. 


\section{References}

${ }^{1}$ Kay JM, Harris P, Heath D. Pulmonary hypertension produced in rats by ingestion of Crotalaria spectabilis seeds. Thorax 1967;22:176-9.

${ }^{2}$ Kay JM, Smith P, Heath D. Electron microscopy of Crotalaria pulmonary hypertension. Thorax 1969;24:511-26.

${ }^{3}$ Heath D, Shaba J, Williams A, Smith P, Combe A. A pulmonary hypertension producing plant from Tanzania. Thorax 1975;30:399-404.

${ }^{4}$ Kay JM, Heath D, Smith P, Bras G, Summerell J. Fulvine and the pulmonary circulation. Thorax $1971 ; 26: 249-61$.

${ }^{5}$ Dahms BB, Halpin TC. Pulmonary arterial lipid deposit in newborn infant receiving intravenous lipid infusion. J Pediatr 1980;97:800-5.

${ }^{6}$ Harris $\mathrm{P}$, Heath D. The human pulmonary circulation. 2nd ed. Edinburgh: Churchill Livingstone, 1977:399-417.

${ }^{7}$ Kay JM, Smith P, Heath D. Aminorex and the pulmonary circulation. Thorax 1971;26:262-70.
${ }^{8}$ Toxic Epidemic Syndrome Study Group. Toxic epidemic syndrome, Spain, 1981. Lancet 1982;ii:697-702.

9 Tabuenca JM. Toxic allergic syndrome caused by ingestion of rape-seed oil denatured with aniline. Lancet 1981;ii:567-8.

${ }^{10}$ Fajardo LF, Berthorone M. Radiation injury in surgical pathology. Am J Surg Pathol 1978;2:159-99.

"Maestro del RF. An approach to free radicals in medicine and biology. Acta Physiol Scand 1980;492:153-68.

${ }^{12}$ McCord JM, Fridowich I. The biology and pathology of oxygen radicals. Ann Intern Med 1978;89:122-7.

${ }^{13}$ Demopoulos HB, Flamm ES, Pietroniero DD, Seligman ML. The free radical pathology and the microcirculation in the major central nervous system disorders. Acta Physiol Scand 1980;492:92-119.

${ }^{14}$ Fernández-Segoviano P, Martínez-Cabruja R, Borregón $A$, et al. Anatomía patológica experimental en modelo animal. In: Symposium Nacional Sindrome Tóxico. Madrid: Ministerio de Sanidad y Consumo, 1982:482-6. 